\title{
Correction to: Multi-directional composite laminates: fatigue delamination propagation in mode $I$-a comparison
}

\author{
Leslie Banks-Sills $\mathbb{i}$ • Ido Simon • \\ Tomer Chocron
}

Published online: 7 January 2020

(C) Springer Nature B.V. 2020

\section{Correction to:}

Int J Fract (2019) 219:175-185

https://doi.org/10.1007/s10704-019-00388-4

Due to an unfortunate turn of events this article which is part of the "GEF-2019" special issue was mistakenly published in the Fracture "Volume 219, Issue 2, October 2019" https://link.springer.com/journal/10704/
219/2. The Publisher and Editor-in-Chief both apologize for the fact that this could have happened.

Publisher's Note Springer Nature remains neutral with regard to jurisdictional claims in published maps and institutional affiliations.

The original article can be found online at https://doi.org/10. 1007/s10704-019-00388-4.

L. Banks-Sills $(\varangle) \cdot$ I. Simon · T. Chocron

Dreszer Fracture Mechanics Laboratory, School of

Mechanical Engineering, Tel Aviv University, 6997801

Ramat Aviv, Israel

e-mail: banks@tau.ac.il

I. Simon

e-mail: idosimon@gmail.com

T. Chocron

e-mail: tomerchocron@mail.tau.ac.il 